\title{
Spring-Value in Kirchhoff-Love Plate: Displacement, Buckling, Pure-Shear, Vibration
}

\author{
Tonye Ngoji Johnarry \\ Rivers State University, Port-Harcourt, Nigeria \\ Email: tnjohnarry@yahoo.com
}

How to cite this paper: Johnarry, T.N. (2021) Spring-Value in Kirchhoff-Love Plate: Displacement, Buckling, Pure-Shear, Vibration. Open Journal of Civil Engineering, 11, 96-118.

https://doi.org/10.4236/ojce.2021.111007

Received: October 23, 2020

Accepted: March 13, 2021

Published: March 16, 2021

Copyright ( 2021 by author(s) and Scientific Research Publishing Inc. This work is licensed under the Creative Commons Attribution International License (CC BY 4.0).

http://creativecommons.org/licenses/by/4.0/

\section{(c) (i) Open Access}

\begin{abstract}
The stiffness model of the finite element is applied to the Kirchhoff-love closed-form plate buckling; buckling is always in focus in plate assemblages. The useful Eigen-value solutions are unable to separate a square plate from a much weaker long one in the most commonly-used all-simply supported plate (SSSS), among others. Spring-values of the Kirchhoff-Love plate are sought; once found, displacement-factors can be determined. Comparative displacements allow an easier and better evaluation of buckling-factors, pureshear, vibration and so are termed "buckling-displacement-factors". In testing, many plates in mixed boundary conditions are evaluated for displacement assisted buckling-solutions, first. The displacement-factors made from fundamental Eigen-vectors, in a single-pass, are found to be within about one-percent of known elastic values. It is found that the Kirchhoff-Love plate spring and the finite-element spring, demonstrated, here, in the assemblage of beam-elements, are equivalent from the results. In either case, stiffness is first assembled, ready for any loading - transverse, buckling, shear, vibration. The simply-supported plate draws the only exact vibration solution, and so, in an additional new effort, all other results are calibrated from it; direct vibration solutions are made for comparison but such results are, hardly, better. In the process, interactive Kirchhoff-Love plate-field-sheets are presented, for design. It is now additionally demanded that the solution Eigen-vector be developable into a recognizable deflection-factor. A weaker plate cannot possess greater buckling strength, this is a check; to find stiffness the deflection-factor must be exact or nearly so. Several examples justify the characteristic buckling displacement-factor as a new tool.
\end{abstract}

\section{Keywords}

Spring-Stiffness, Rectangular Plates, Deflections, Buckling, Pure-Shear, 


\section{Introduction}

\subsection{Thin Plate Displacement}

In the area of plate bending and displacement, Timoshenko and Krieger [1], remains a veritable source of reference including the contribution of many other expert-authors. The closed-form results of these experts are approximately but closely re-established by the numerical finite-element process since its inception about 1965; plate-stiffness reduces as loaded surface area increases, it was established. In the study of buckling here, a new fast but competitive displacement solution, based on domain spring-stiffness, is found and described.

\subsection{Buckling-Beam/Plate}

Euler's Eigen-vector $(Z \sin \pi x / L)$ for his original bar was not developed into a displacement-factor, $(\Delta)$. Buckling discovery quickly found applications in stability in frames of construction; in plates making up ships and air-planes, etc. With Kirchhoff-Love displacement-theory on the scene, the attendant Euler's buckling displacement-factor should have been found given Euler mode $(W=Z \sin \pi x / L)$.

Give a Value to the Kirchhoff-Love Differential, " $\left(\partial^{4} w / \partial x^{4}\right)$ "

$$
H_{x x}=\frac{\partial^{4} w}{\partial x^{4}}=\frac{\partial^{4} w / \partial x^{4}}{1}=\frac{\iint w\left(\partial^{4} w / \partial x^{4}\right) \partial x \partial y}{\iint w \partial x \partial y}
$$

Find $H_{x x}=Z(1 / 4) \pi^{5} / L^{4}, H_{x x}=76.4977 Z$, and, $\Delta_{i}=Z W_{\text {shape }}=0.013077 q^{*} L^{4} / D^{*}$-maximum.

There is nothing to separate this result from the Euler-Bernoulli beam displacement, $-5 / 384=0.01302$

A work-energy solution comes for comparison, not that it is essential. The reactive-capacity of the plate is first determined in terms of normal and twisting reactions for virtual continuous-loading.

The treatise of Arthur, W. Leissa, [2], 1985, gives a comprehensive discourse in buckling, encompassing shear-buckling. The complexities in buckling solutions quickly become apparent in the very first problem in "SSSS" where the square-plate and another " 1 . by 2 ." solve exactly the same value of " $N_{c r} \equiv 4$ " in uni-axial compression. Studies by Yaghoobi [3] found that a " 1 by 1.5 " SSSSplate was 91-percent as strong as square plate in buckling. Experiments in buckling [4] [5] [6] show the same trend. The expected buckling-strength versus aspect-ratio of the "SSSS" plate in uni-axial compression is expected to be "Graph-B" rather than the stronger existing graph-A. The difference is important and has implications in many other situations including pure-shear. Al- 
ready shown, Euler beam-buckling " $E I \cdot \partial^{4} w / \partial x^{4}=F \cdot \partial^{2} w / \partial x^{2}$ " comes with a unique deflection factor of " $0.013077 L_{x}^{4} /(E I)$ " in a fundamental Sine-mode, close to the "0.01302 $L^{4} / E$ ?' for "Euler-Bernoulli" beam in a polynomial statics mode; they play different roles. The buckling load of the "SSSS-plate" cannot have the same result between the aspect-ratios of 1.0 and " $\infty$ " as exhibited in existing monographs, as handed down since [1] [2]. The present study explains why it is untenable.

In Johnarry and Ebitei, [7] [8], buckling was tracked by displacement and the Euler-type Curve-B in Figure 1, was achieved; the buckling strength of infinitely long "SSSS-plate" reduced significantly below the "4.0" literature value, [1] [2]. Similar improvements were found in other cases and especially the pure-shear cases [8] [9] [10].

\subsection{Pure-Shear}

Pure-shear must always be investigated in plates, webs, and beam-column joints; indeed at all supports. The studies of Johns [9], Rockey [10] give great insights. This new spring-capacity solution of the "SSSS-plate" is carried over to the pure-shear case and it was found the existing solution, " $N_{x y} \equiv 5.351+4 /\left(1+(a / b)^{2}\right)$ ” was too high [9], vis-à-vis a new solution [8], “ $N_{x y} \equiv 3.65+4 /\left(1+(a / b)^{2}\right)$ ”. The webs of beams in service are highly affected by pure-shear effects leading to wrinkling/buckling tending to change an existing shape; Figure 2. Pure shear always accompany heavy loading/reaction zones; buckling and pure-shear are composite in nature. It will be shown.

\subsection{Vibration}

Vibration of plates continues to be an on-going study; unforeseen alarming vibration in cable-stayed bridges and recently in the London millennium foot-bridge (Year-2000) are recent cases. This is despite major design consideration of vibration in such cable-assisted long spans learning from earlier historic failures. Key aspects of early studies in vibration was due to Lord Rayleigh, [11], 1945 , who confirmed that the free-vibration-factor of a simply-supported plate was “ $\omega^{2}=4 \pi^{4} D / \mathfrak{M}$ ”. Many earlier results, up to 1966 , were compiled by Bhalchandra Ballal, [12] showing that the then best all-clamped square-plate (CCCC) result was " $\omega \equiv 35.98$ " by "Iguchi" which is now known to be some $2.5 \%$ upper-bound. More recent extensive study and information on plates in free vibration are found in Authur M. Leissa [13] and in Xing and Liu, 2008 [14] who elaborated Levy-type deflection functions into characteristic equations and determinate de-composition for exact solutions; the lower-bound clamped frequency-factor for the "CCCC" was found [14] to be " $\omega \equiv 35.112$ " (lowest ever found). Adopting Navier-type conventional plate-bending analysis procedure should also yield comparable vibration results. Other simpler solutions are easily found equating potential and kinetic energies after Rayleigh-Ritz; or comparing 


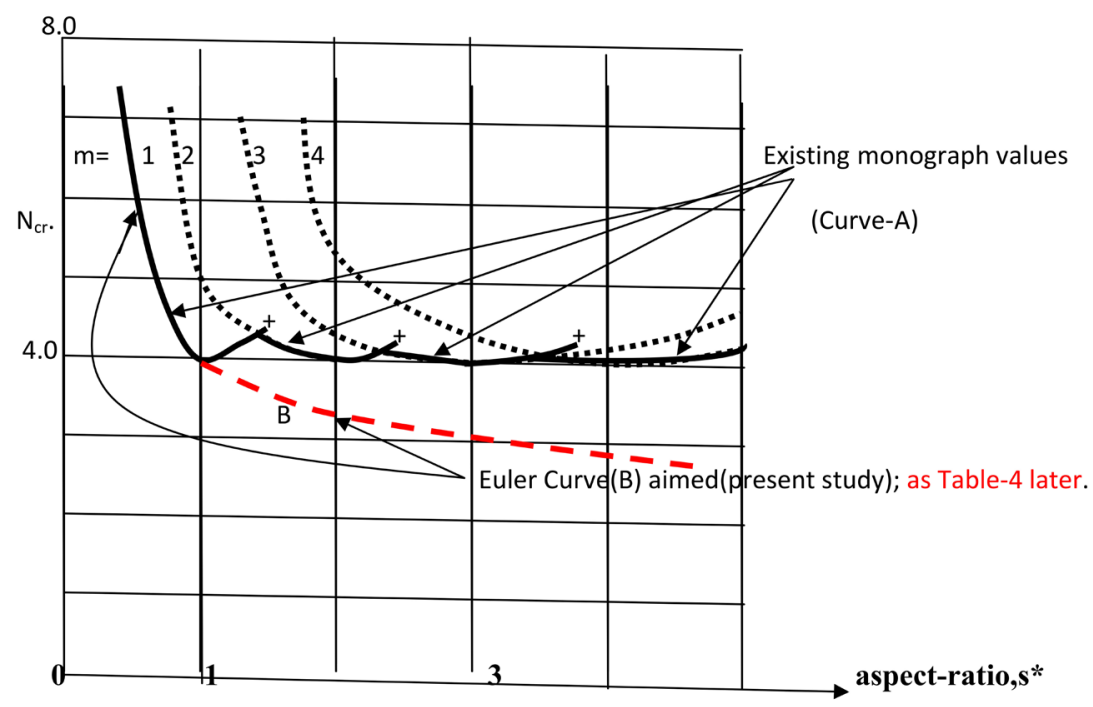

Figure 1. SSSS-plate; buckling-factor vs aspect-ratio; $W=Z(\sin m \pi x / a)(\sin n \pi y / b)$.

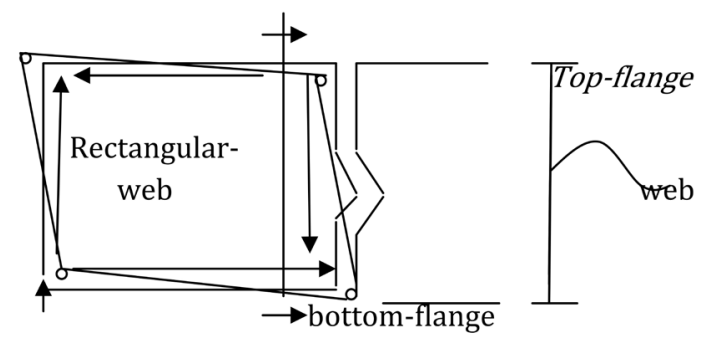

Figure 2. Pure-shear trying to distort rectangle of I-beams's web.

of energy-work potentials in a Galerkin solution. Onwuka, et al., [15] used such a technique with results, only 2.47-percent higher than Xi and Liu. [14] in frequency-factor, " $\omega$ " in the "CCCC". So there had been good solutions since before 1966; what is essential now seems to be simpler self-checking design-oriented method as found in this new study through calibration from the exactly known all-sides simply supported plate.

The study of natural frequencies of materials and structures take pre-eminent stage because of effects of dynamic forces. The British Standard-5400, [16] prescribes dynamic forces in foot bridges as moving point-load of

“ $F(t)=180 \operatorname{sine}(\omega \cdot t)$ ” Newtons, simplifying dynamic designs. Similar suggestions can be made in other areas; the force " $F(t)$ " can be an equivalent "Category-5 hurricane".

\subsection{Finite-Element, (FE)-Stiffness-Solution and Kirchhoff-Love Plate-Stiffness Solution}

The finite-element method basically comes down to "Stiffness-displacement-Load" $[K]\{\Delta\}=\{F\}$ equalit; by comparison, the Kirchhoff-Love plate equation for beam $(w=Z f(x))$ leads to Equation (1), where, $[K]\{Z\}=\left\{q_{e}\right\}$. Both springs are basical- 
ly the same; the former is, simply, more elaborate. The $\{F\}$, takes different forms for bending, buckling, vibration. In the particular case of buckling it is bending-moment, $F \equiv\left\{M_{i}\right\} ; P_{c r} / N_{\text {euler }}=\left(M_{\text {relative }} / \Delta\right) / N_{\text {euler }} \equiv$ "moyope" in Table 1. In Ref. [17] with extensive computer buckling solutions print-outs, it was proved that finite-element beam-buckling followed "Sine variation". For example the finite-element solution started as though the Sine-variation was not known and the initial loading was uniform, $\{q\}$; then replace $\{q\}$ by the found $\{M\}$ and keep replacing by new $\{M\}$ until a steady state situation is found in three or four iterations. The closed-form solutions were, very accurately, re-established. The "FE" analysis in Table 1 for fixed-base sway-portal $\left(I_{\text {beam }} / I_{c o l}=0.1\right)$, buckling analysis is output- $N_{c r, c o l}=0.252 N_{\text {euler }}$. This is virtually the buckling of cantilever-column. (notice the steady-state solution). Tbe portal frame case is an extended beam analysis and only the beam-column finite-element is tested. By calling " $I_{b} / I_{c}$ " $=\infty$ (say, 100); " $N_{c r}=N_{\text {euler }}$ ", and so on For beam from point-1 to point-2. length- $L$, the local stiffness elements are found. The matching $\Delta$-vector reads $\left\{u, \Delta_{1}, \theta_{1}, \Delta_{2}, \theta_{2}\right]$ and the relevant force-action vector reads, $\left\{N, V_{1}, M_{1}, V_{2}\right.$, $\left.M_{2}\right\}$.

The logical sequence is, "[ $\left.K_{\text {local }}\right] \rightarrow[$ Transform $] \rightarrow\left[K_{\text {global }}\right]$; explaining $\left[K_{\text {local }}\right]$ as the basic slope-deflection, Table 2, with, $r=E I / L$; $a^{*}=A E / L^{\prime \prime} ; C_{22}=12 \mathrm{r} / \mathrm{L}^{2}$; and $C_{23}=-6 r / L ; C_{25}=6 r / L$.

\subsection{Objective}

In the "SSSS" plate, among others, buckling Eigen-values are unable to differentiate a square plate from a long one to the detriment of design. It will now be possible to specify buckling strength with characteristic displacement-factor to overcome this problem. It has already been shown the first Euler bar should have specified the characteristic-displacement, " $\Delta=0.013077 q^{*} L^{4} / E I$ ” from the solution Eigen-vector; it should have been the practice.

Uni-axial strength versus aspect-ratio buckling curves handed-down by experts, [1] [2] are connected individual mode-curves with unknown junction-values except by extrapolation; the present study will find continuous variation.

It will be shown that characteristic buckling displacement exists, (akin, to the Southwell-plot). Such relative-displacements find near-exact vibration-factors through calibration from the exact "SSSS" values.

\section{Applicable Equations}

\subsection{Bending and Deflection in Thin Plates}

$$
\frac{\partial^{4} w}{\partial x^{4}}+\frac{2 \partial^{4} w}{\partial x^{2} \partial y^{2}}+\frac{\partial^{4} w}{\partial y^{4}}=\frac{q}{D}
$$

By expressing the deflection- " $W$ " and the load " $q$ " into similar infinite series Timoshenko and others have comprehensively explained the solutions for displacements and bending moments. 
Table 1. Fixed-base portal + mirror, itertn $=3$; bars-34; $\left(I_{\text {beam }}\right) /\left(I_{\text {col }}\right)=0.1$.

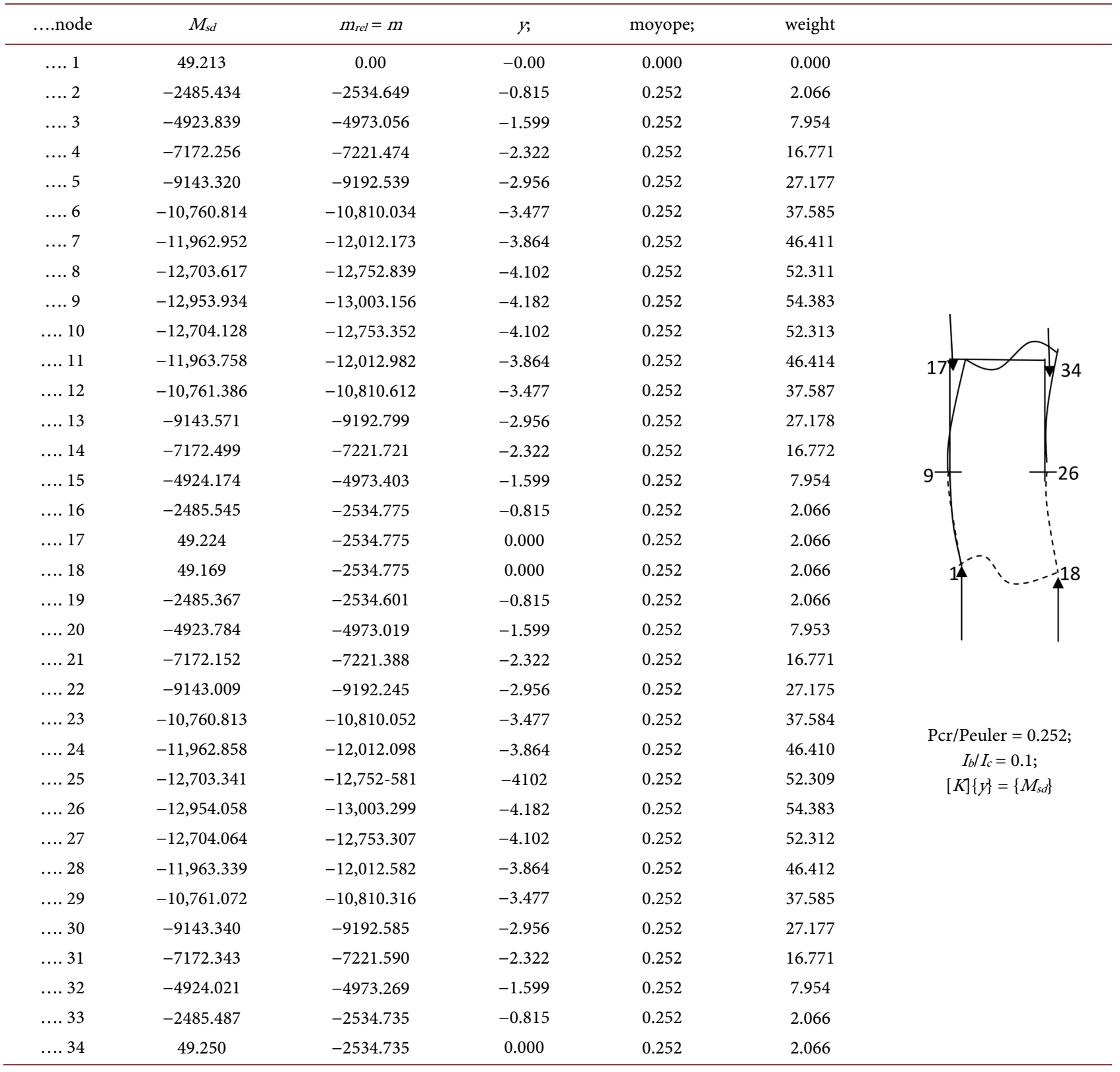

Table 2. Local beam matrix, (Klocal) elements.

\begin{tabular}{ccccc}
\hline$a^{*}$ & 0 & 0 & 0 & 0 \\
\hline 0 & $-C_{22}$ & $C_{23}$ & $C_{22}$ & $-C_{25}$ \\
0 & $C_{25}$ & $4 r$ & $-C_{25}$ & $2 r$ \\
0 & $C_{22}$ & $C_{25}$ & $C_{25}$ & $4 r$ \\
0 & $C_{25}$ & $2 r$ & $-C_{22}$ & 4 \\
\hline
\end{tabular}

\subsection{Plate Buckling-Isotropic}

\section{(a) Bi-axial:}




$$
\frac{\partial^{4} w}{\partial x^{4}}+\frac{2 \partial^{4} w}{\partial x^{2} \partial y^{2}}+\frac{\partial^{4} w}{\partial y^{4}}=\frac{N_{x}\left(\partial^{2} w / \partial x^{2}\right)+N_{y}\left(\partial^{2} w / \partial y^{2}\right)}{D}
$$

(b) Uni-axial in $X$ :

$$
\frac{\partial^{4} w}{\partial x^{4}}+\frac{2 \partial^{4} w}{\partial x^{2} \partial y^{2}}+\frac{\partial^{4} w}{\partial y^{4}}=\frac{N_{x}\left(\partial^{2} w / \partial x^{2}\right)}{D}
$$

Many solutions of this are found in Ref. [2] and elsewhere but some are untenable, especially when the compressed ends are simply-supported.

(c) Pure-Shear:

$$
\frac{\partial^{4} w}{\partial x^{4}}+\frac{2 \partial^{4} w}{\partial x^{2} \partial y^{2}}+\frac{\partial^{4} w}{\partial y^{4}}=\frac{N_{x y}\left(2 \partial^{2} w / \partial x \partial y\right)}{D}
$$

Pure-shear solutions are not as available as the earlier two.

The method employed, here, is to relate the critical curvature in uni-axial compression to the von Misses distortion shear, $\left(\sigma_{V M}\right)$, and associated curvature, " $\chi_{V M}$."

$$
\begin{gathered}
\frac{\partial^{4} w}{\partial x^{4}}+\frac{2 \partial^{4} w}{\partial x^{2} \partial y^{2}}+\frac{\partial^{4} w}{\partial y^{4}}=\frac{N_{x y} \chi_{V M}}{D} \\
2 \sigma_{V M}^{2}=\left[\sigma_{1}-\sigma_{2}\right]^{2}+\left[\sigma_{2}-\sigma_{3}\right]^{2}+\left[\sigma_{3}-\sigma_{1}\right]^{2}
\end{gathered}
$$

Or, in respect of curvature, $(\chi)$

$$
\sigma_{V M}=C \cdot \chi_{V M}
$$

By Equations $(5,6)$ pure-shear is known with uni-axial buckling curvatures, [8].

\subsection{Plate Vibration with Circular-Velocity- $\omega$, at Time-t}

$$
\frac{\partial^{4} w}{\partial x^{4}}+\frac{2 \partial^{4} w}{\partial x^{2} \partial y^{2}}+\frac{\partial^{4} w}{\partial y^{4}}=\frac{\mathfrak{M}\left(\partial^{2} w / \partial t^{2}\right)(W \sin \omega \cdot t)}{D}
$$

Or, with respect to dimension " $x, y$ " only, for the eventual vibration equation,

$$
\frac{\partial^{4} w}{\partial x^{4}}+\frac{2 \partial^{4} w}{\partial x^{2} \partial y^{2}}+\frac{\partial^{4} w}{\partial y^{4}}=\frac{\mathfrak{M}\left(\omega^{2}\right) \cdot W_{\text {mode }}}{D}
$$

To tie buckling and vibration, the next equation, Equation (9a), ensues; find $\left[K_{v i b}\right]$

$$
\begin{gathered}
K_{b u c} \Delta_{b u c}=K_{v i b}\left(\Delta_{b u c}+\sum \Delta_{\text {hamonics }}\right) \\
\omega^{2}=\frac{K_{v i b}}{\mathfrak{M}}
\end{gathered}
$$

If buckling or elastic displacements were known, an alternate easier method using the "SSSS" as calibrator is,

$$
\omega_{\text {next }}^{2} \cdot \Delta_{\text {next }}=\omega_{\text {ssss }}^{2} \cdot \Delta_{\text {ssss }}
$$


Or, simply for a constant plate-thickness, even for the same boundary conditions,

$$
\omega_{1}^{2} \cdot \Delta_{1}=\omega_{2}^{2} \cdot \Delta_{2}
$$

The implication is that if the $\left(\omega^{2}\right)$ is known for one aspect-ratio the value for another aspect-ratio with known " $\left(\Delta_{2}\right)$ " is readily found. For example, for the "SSSS" with " $a / b=1$ " and $\omega_{1}^{2}=389.6$ and " $\Delta_{1}$ " $=0.00416$ then at " $a / b$ " $=2$ with " $\Delta_{2}$ " $=0.0106$, then, $\omega_{2}^{2}=152.9$, or, $\omega_{2}=12.36$; that is all; there is no need to solve, afresh, the case, " $a / b "=2$ (see Table 3, Table 4).

Relating the "SSSS" to "CCCC" for any aspect-ratio, the formula applies; for example, CCCC at $a / b=1: \Delta_{c c c c} \rightarrow 0.00128$, then

$\omega_{c c c c}^{2} \rightarrow(0.00416 / 0.00128) \times 389.6=1266, \omega_{c c c c}=35.58 \ldots$ a result very difficult to improve upon, [12] [13] [14] [15].

\section{Spring-Capacity of the Kirchhoff's Plate Differentials}

By giving finite values of the left-hand differentials, the capacity of a Kirchhoff s plate is identified; this is achieved through valid deflection functions,

" $W=Z W_{\text {shape }}$ "

$$
\begin{gathered}
H_{x x}=\partial^{4} w / \partial x^{4}=\frac{\iint w\left(\partial^{4} w / \partial x^{4}\right) \partial x \partial y}{\iint w \partial x \partial y} \\
H_{x y}=2 \partial^{4} w / \partial x^{2} \partial y^{2}=\frac{\iint 2 w\left(\partial^{4} w / \partial x^{2} \partial y^{2}\right) \partial x \partial y}{\iint w \partial x \partial y} \\
H_{y y}=\partial^{4} w / \partial y^{4}=\frac{\iint w\left(\partial^{4} w / \partial y^{4}\right) \partial x \partial y}{\iint w \partial x \partial y}
\end{gathered}
$$

Taking " $\mathcal{X}$ ” as curvature;

$$
\begin{aligned}
& \mathcal{X}_{x}=\partial^{2} w / \partial x^{2}=\frac{\iint w\left(\partial^{2} w / \partial x^{2}\right) \partial x \partial y}{\iint w \partial x \partial y} \\
& \mathcal{X}_{y}=\partial^{2} w / \partial y^{2}=\frac{\iint w\left(\partial^{2} w / \partial y^{2}\right) \partial x \partial y}{\iint w \partial x \partial y} \\
& \mathcal{X}_{1,2}=\frac{\mathcal{X}_{x}+\mathcal{X}_{y}}{2} \pm \frac{\sqrt{\left(\mathcal{X}_{x}-\mathcal{X}_{y}\right)^{2}+\mathcal{X}_{x y}^{2}}}{2}
\end{aligned}
$$

Or by reference to the Mohr's circle, for " $R$ " as radius,

$$
\mathcal{X}_{1,2}=\frac{\mathcal{X}_{x}+\mathcal{X}_{y}}{2} \pm R
$$

These integrals are the outcomes of criterion of buckling as relative-curvature/deflection resonance. A typical buckling resistance integral is,

$$
\partial^{4} w / \partial x^{4}=C_{x d 4}\left(w_{x x-r} / w\right)=C_{x d 4}\left(R_{x c d}\right)
$$

The ratio, " $w_{x x-r} / w=R_{x c d}$ " must always be a scalar constant or else the func- 
tion is inadmissible; indeed this is the inbuilt buckling criteria. Buckling deflection function, $w$, must be chosen as to make the ratio, $\left(w_{x x-r} / w\right)$, a scalar. The domain compliant factor at resonance, $C_{x d 4}$, is what is left to be found. Multiply through and integrate to find it.

$$
C_{x d 4} \cdot R_{x c d}=\partial^{4} w / \partial x^{4}=\frac{\iint w\left(\partial^{4} w / \partial x^{4}\right) \partial x \partial y}{\iint w \partial x \partial y}
$$

\subsection{Displacement in Bending/Buckling in Rectangular Plate}

The deflection function, $w$, is taken as

$$
w=Z\left[w_{s h p, x}\right]\left[w_{s h p, y}\right]
$$

The "SSCS" is considered in X-hydrostatic load $q=q_{0}(x / a)$; Figure 3.

Bending was, initially, not the focus of the present study; this has been better treated elsewhere [1]. The relative deflections, as found here, needed for the studies in buckling, pure-shear, vibration are seen to be virtually, interchangeable with the bending ones.

(a): "SSCS"-Plate, Figure 3

1) $w=Z[\sin G \cdot x / a+A \cdot x / a][\sin n \pi y / b]$

For $n=1, G=4.5$ and “ $A$ " $=0.977$.

2) $w^{*}=\iint w \partial x \partial y \rightarrow 0.482$

3) $H_{x x}=\frac{\iint w\left(\frac{\partial^{4} w}{\partial x^{4}}\right) \partial x \partial y}{w^{*}}$

yielding, $\rightarrow$ “ $0.225 G^{4} / a^{4} / w^{*} \rightarrow 191.42 ”$.

4) $H_{x y}=\frac{\iint 2 w\left(\frac{\partial^{4} w}{\partial x^{2} \partial y^{2}}\right) \partial x \partial y}{w^{*}}$

yielding, $\rightarrow$ “ $0.45 G^{2} \pi^{2} / w^{*} \rightarrow 186.6 ”$.

5) $H_{y y}=\frac{\iint w\left(\frac{\partial^{4} w}{\partial y^{4}}\right) \partial x \partial y}{w^{*}}$

yielding, $\rightarrow$ “ $\left(0.384 / b^{4}\right) n^{4} \pi^{4} / w^{*} \rightarrow 77.6 ”$.

Summing, $\left.H:\left(H_{x x}+H_{x y}+H_{y y}\right)=455.6\right]$; noting, this spring-value will solve any loading for this plate.

Find " $\Delta_{c r}=(1 / H) W_{\text {shp }} q_{\text {norm }}$ ".

Find $\left(q_{\text {norm }}\right)$ as $\left[\frac{q_{i} \cdot w_{i}}{w_{i}}\right]$ by quadrature if not constant $-q_{0}$.

from points $(0.5,0.75) ;(0.25 .0 .5) ;(0.5,0.5) ;(0.75,0.5) ;(0.5,0.25)$,

find, $\left(q_{\text {norm }}\right)$ as $\left(0.466 q_{0}\right)$ and so, $\Delta_{c r} \rightarrow(1 / H) \times 1.266 \times 1.0 \times 0.466 \rightarrow 0.001295$; cf, $0.0013,[1]$. 


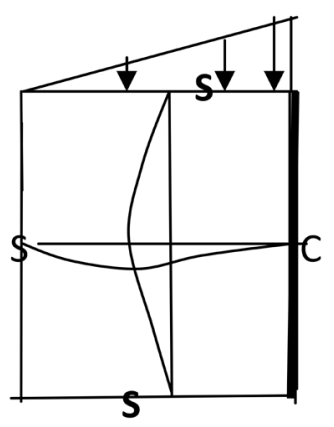

Figure 3. "SSCS" Plate in X-hydrostatic bending-load; $q_{0} x / a$; try case of " $a / b=1$ ".

The solution is in the context of the "finite-element-method: $[K]\{\Delta\}=F$. In this case $[K$ or $H]=455.6$.

(b): "udl case": If " $q_{\text {norm }} \equiv q_{0}$; udl, $\Delta_{c r} \rightarrow 0.001295 /(0.466) \rightarrow 0.002779$; cf, 0.0028 [1]. The new method is, therefore, self-checking.

\subsection{Buckling Potential Limits}

Three possibilities are identified relative to $\mathrm{X}$ - and $\mathrm{Y}$-axes in emulating the reactive potentials " $\left[\partial^{4} w / \partial x^{4}\right] ;\left[2 \partial^{4} w / \partial x^{2} \partial y^{2}\right] ;\left[\partial^{4} w / \partial y^{4}\right]$ ". No curvature " $\mathcal{X}_{i}$ " is ever applied in practice but " $\mathcal{X}_{x}$ " and " $\mathcal{X}_{y}$ " act jointly.

1) $\sigma_{x} \mathcal{X}_{x}$

This is first in contention in uni-axial X-compression; this case easily solves Equations $(3,4)$.

2) $\sigma_{y} \mathcal{X}_{y}$

This is out of contention when no load is applied in the Y-axis, whatever the value of “ $\mathcal{X}_{y}$."

3) $\sigma_{x} \mathcal{X}_{a v}$

This "average loading-curvature" situation will always happen and also in contention. 1) and 2) are identified in the Mohr's diagram, Figure 4.

In effect, two curvature-loading circles $\left(\mathcal{X}_{x}, \mathcal{X}_{a v}\right)$ are operative and the larger circle gives the required solution for " $N_{x}^{\prime}$. This process softens the stiff constraint that the wave numbers " $m, n$ ", must be whole numbers.

(a). Importance of Curvature, " $\left(\partial^{2} w / \partial x^{2}\right)_{c r}$ ", in Uni-axial-Compression Buckling

The solution of Equation (3). is easy when

1): when, " $\partial^{2} w / \partial x^{2} \geq \partial^{2} w / \partial y^{2}$ "

or

2) when, $\mathcal{X}_{x}=\mathcal{X}_{c r}=\partial^{2} w / \partial x^{2}$

When " $\partial^{2} w / \partial x^{2}<\partial^{2} w / \partial y^{2}$ ”, “ $\mathcal{X}_{1}$ ” may be interpreted as principal loading curvature that must align with " $\left(\partial^{2} w / \partial x^{2}\right)$ " approximately or else find $(\chi)$ by equation (20).

So, Figure 4, explaining Mohr's loading curvatures will supply the critical solution curvature. 


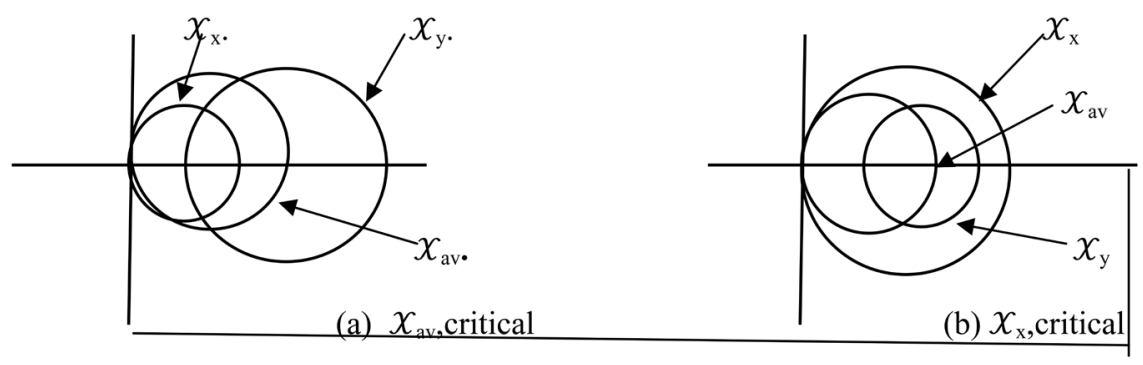

Figure 4. Buckling curvature-loading-circles; $\mathrm{X}$-compression; exact if $\mathcal{X}_{x} \geq \mathcal{X}_{y}$.

\section{(b)-Alternate Critical X-Curvature, " $\left(\partial^{2} w / \partial x^{2}\right)_{c r}$ " By Deflection Ratio}

Relying on the deflection coefficients, $\Delta_{1}, \Delta_{2}$ at two consecutive locations, " $i$ " and " $i+1$ ", Figure 5(a), the curvature at the second location may be found from Equation (17)

$$
\frac{\Delta_{1} \mathcal{X}_{x, 1}}{A_{1}}=\frac{\Delta_{2} \mathcal{X}_{x, 2}}{A_{2}}
$$

$A_{2} / A_{1}=C_{A}$, stressed boundary lengths-ratio representing side areas; Figure 5(b), Figure 5(c).

Aspect ratio, " $s$ " gap of 25-percent can be tolerated.

This equation is similar to Equation (3) as "(Force/Area)(curvature) = Constant" = Kirchhoff's plate-capacity.

$$
A=2 b+\frac{2 a t}{3}
$$

\subsection{Deflection-Factor as Part of Buckling Solution}

From Equation (4), put, $N_{x}\left(\partial^{2} w / \partial x^{2}\right) \equiv q^{*}$; for a given plate the "LHS" is invariant and once computed can be used for bending, buckling and vibration; " $q$ " is equivalent uniform transverse pressure. That is, $\Delta \equiv(1 / H) w_{\text {shape }}$; the primitive buckling-value is sufficient. The familiarity of " $\Delta$ value" gives confidence the solution is on track.

\section{Illustrations: Buckling Including Pure-Shear $\left(N_{x y}\right)$}

\subsection{Buckling-Plate; "SCCC", Figure 6}

(a); $a / b=0.95$; Deflection in Buckling

$$
w=Z[\sin G \cdot x / a+A \cdot x / a][1-\cos n \pi y / b]
$$

in which, " $n=2 ; G=4.5 ; A=0.977 ; b=1$ ".

By Equation (19), find, $w^{*}=0.757$.

By Equation (20), find " $H_{x x}$ " as $\rightarrow\left(0.675 G^{4} / a^{4}\right) / w^{*} \rightarrow 365.74 / a^{4}$

By Equation(21) find " $H_{x y}$ " as $\rightarrow 0.45 n^{2} \cdot \pi^{2} \cdot G^{2} / a^{2} \cdot b^{2} \rightarrow 475.24 / a^{2}$

By Equation (22), find " $H_{y y}$ " as $\rightarrow\left(0.383 n^{4} \cdot \pi^{4} / b^{4}\right) / w^{*} \rightarrow 788.46$

Find curvatures, 


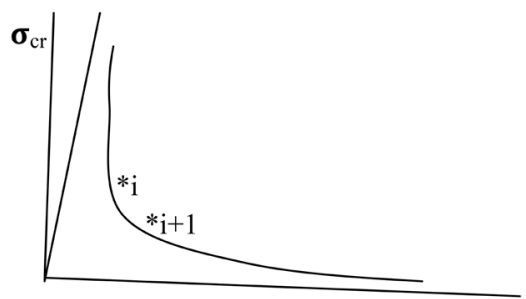

(a)

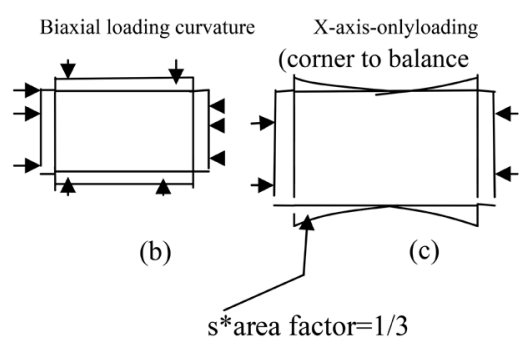

Figure 5. (a) Expected buckling stress-aspect ratio curve; (b)Biaxial stress-form; (b) Uniaxial stress form.

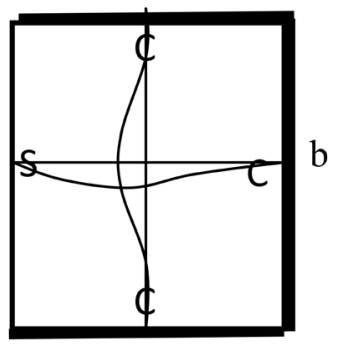

a

Figure 6. Buckling-plate "SCCC"; $a / b=$ 0.95 where " $\chi_{x \text {-domain }}=\chi_{y \text {-domain }}$.

$$
\chi_{x}=\frac{\iint w\left(\partial^{2} w / \partial x^{2}\right) \partial x \partial y}{w^{*}}
$$

yielding, $\rightarrow$ “ $\left(0.675 K^{2} / a^{2}\right) / w^{*} \rightarrow 18.056 / a^{2} "$.

$$
\chi_{y}=\frac{\iint w\left(\partial^{2} w / \partial y^{2}\right) \partial x \partial y}{w^{*}}
$$

yielding, $\rightarrow$ “ $\left(0.383 n^{2} \cdot \pi^{2} / b^{2}\right) / w^{*} \cong 20.03 / b^{2} ”$.

Evaluating, $a / b=0.95 ;\left[\mathcal{X}_{x}=18.06 / 0.95^{2}=20.0\right] ;\left[\mathcal{X}_{y}=20.03 \equiv 20\right] ;\left[H_{x x}=\right.$ 448.49; $\left.H_{x y}=526.58 ; H_{y y}=788.46 ; H=1763.53\right]$;

$\Delta_{s^{*}=0.95}=W_{\text {shp-c }} / H \rightarrow \Delta_{c r}$; find $W_{s h p} \rightarrow\left(W_{s h p, x}\right)\left(W_{s h p, y}\right) ;$ at $x / a=0.4$ and $y / b=0.5$, $W_{\text {shp }} \rightarrow 2.73$; (compare the shape-value of "CCCC"-plate at center of bending $\rightarrow$ " $w_{\text {shp }}=4$ ", from function. $W \equiv Z(1-\cos 2 \pi y / a)(1-\cos 2 \pi y / b)$. So, $\Delta_{c r} \rightarrow$ 0.00155 .

Curvature and Buckling Value, $(a / b=0.95), N_{x, c r}$

$\rightarrow N_{x, s^{*}=0.95}=H / \mathcal{X}_{x, c r} \rightarrow 8.93 \rho$ (expected to be exact).

(b) Try New Aspect-Ratio, $a / b=1$; the "SCCC"; $H=1627 ; \chi_{x}=18.88$ (with help of Equation (23))

$N_{x, s^{*}=1} \rightarrow 1627 / 18.88 \rightarrow 8.73 \pi^{2} ;$ cf. 8.986, [2]; table is skipped similar to Table 6.

\subsection{CCCC-Plate}

(a) The "CCCC" buckling-plate; " $\Delta$-method"; Table 3 


$$
w=Z\left[1-\cos \frac{m \pi x}{a}\right]\left[1-\cos \frac{n \pi y}{b}\right]
$$

in which,; $m, n=2, \ldots$

(i): $a / b=1$; By Equations $(20,21,22,25,26), H_{x x}=1168.8 ; H_{x y}=779.2$; $\mathcal{X}_{x}=\mathcal{X}_{y}=\mathcal{X}_{c r}=29.608 ; H_{y y}=1168.8 ; H=3116.8$;

$N_{s^{*}=1}=31168.8 / 29.608=10.66 \rho ; \Delta_{c}=0.00128 ; \mathrm{cf}, 0.00126$ [1]; the nearness of the primitive- $\Delta$ to the final- $\Delta$, $(0.00128$ to 0.00126$)$, confirms " $H$ " on which " $N_{x}$ " depends. Further, the exactness of the $w$-function is verified.

(b) More Results: More results are found in Table 3

The "CCCC" is sampled in Table 3 in the " $\Delta$-method" to reflect aspect-ratios; for “ $\mathcal{X}_{i}$ ” from “ $\mathcal{X}_{i-1}$ ”.

\subsection{The "SSSS" Plate}

( $\Delta$-method), is compiled in Table 4 , for “ $w=Z(\sin \pi x / a)(\sin \pi y / b)$ ".

\subsection{The "CSCS" Plate, Table 5}

$$
w=Z\left[1-\cos \frac{m \pi x}{a}\right][\sin \pi x / a]
$$

where $m=2$; results are displayed in Table 5; at $s^{*}=1$ the $\Delta$-factor, 0.00194 , are very accurate in the same fashion as the "CCCC" plate in Table 3. The results for pure-shear match the literature "SSSS" values and so the "SSSS" literature-values are untenable. The new "SSSS" pure-shear values as given in Table 4 are only about $60 \%$ of those of 'CSCS' in Table 5.

\begin{tabular}{|c|c|c|c|c|c|c|c|c|c|c|}
\hline $\begin{array}{c}\mathcal{S}^{*} \\
(1)\end{array}$ & $\begin{array}{l}\Delta_{s^{*}} \\
(2)\end{array}$ & $\begin{array}{l}C_{A} \\
\text { (3) }\end{array}$ & $\begin{array}{l}\mathcal{X}_{\Delta} \\
(4)\end{array}$ & $\begin{array}{l}\left(K_{\text {buc }}\right) \\
(5)\end{array}$ & $\begin{array}{c}\mathcal{K}_{c r} ;[\text { Ref.-2] } \\
(6)\end{array}$ & $\begin{array}{c}x_{\mathrm{VM} .}=x / \sqrt{ } 2 \\
\left\{\mathrm{~N}_{\mathrm{xy}}\right\} \\
(7)\end{array}$ & $\begin{array}{l}K_{v i b} \\
(8)\end{array}$ & 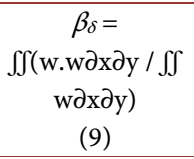 & $\begin{array}{c}\omega=\sqrt{8} / 9 \\
(10)\end{array}$ & $\begin{array}{c}\text { Monitor }= \\
(\delta \mathcal{X} / \delta \Delta) / \Delta \\
\quad(11)\end{array}$ \\
\hline 1 & 0.00128 & & 29.61 & 3116.8 & $10.66 \rho,[10.4]$ & $\begin{array}{c}20.93 \\
\{15.08\}\end{array}$ & 2856 & 2.25 & $\begin{array}{c}35.6\{37 . \text { at for } \\
m=n=2\}\end{array}$ & - \\
\hline 1.25 & 0.00186 & 1.05 & 21.72 & 2146.2 & $10.01 \rho,[9.9]$ & & & & & $-13,600$ \\
\hline 1.5 & 0.00229 & 1.071 & 19.00 & 1746.0 & $9.3 \rho,[9.3]$ & & 1599 & 2.25 & 26.6 & -6326 \\
\hline 1.75 & 0.00258 & 1.055 & 18.06 & 1547.85 & $8.68 \rho,[8.6]$ & & & & & -3241 \\
\hline 2.0 & 0.002784 & 1.053 & 17.88 & 1436.65 & $8.14 \rho,[8.0]$ & & 1316 & 2.25 & 24.2 & -900.0 \\
\hline 2.25 & 0.002923 & 1.051 & 17.88 & 1368.3 & $7.75 \rho,[7.7]$ & & & & & 0 \\
\hline 2.35 & 0.002967 & 1.019 & 17.88 & 1348.2 & $7.64 \rho$ & & & & & 0 \\
\hline 2.45 & 0.003005 & 1.019 & 17.88 & 1331.05 & $7.54 \rho$ & & & & & 0 \\
\hline 2.5 & 0.003022 & 1.009 & 17.88 & 1323.39 & $7.50 \rho,[7.5]$ & & & & & 0 \\
\hline 2.75 & $\begin{array}{c}0.00309 \\
(0.00302)\end{array}$ & 1.045 & $\begin{array}{c}18.24 \\
(17.88)\end{array}$ & 1292.5 & $7.32 \rho$ & & 1183 & 2.25 & 22.9 & +473.2 \\
\hline 3 & 0.00302 & 1.0526 & $\begin{array}{c}18.70 \\
(17.88)\end{array}$ & 1292.5 & $7.32 \rho,[7.35]$ & $\begin{array}{l}13.22 \\
\{9.91\}\end{array}$ & & & & \\
\hline
\end{tabular}

Table 3. New results of "CCCC" and $s^{*} ; \quad N_{x}=\rho \mathcal{K} ;$; $\mathcal{X}$ ” By “ $\Delta$ "; $\left(\Delta_{i} \equiv W_{\text {sh }} / H\right)$; buckling and vibration. 
Table 4. New results of "SSSS" and $s^{*} ; N_{x}=\rho \mathcal{K}_{c r} ;$ “ $\mathcal{X}$ ” By “ $\Delta$ "; $\left(\Delta_{i} \equiv W_{s h} / H\right)$; buckling, vibration.

\begin{tabular}{|c|c|c|c|c|c|c|c|c|c|c|}
\hline $\begin{array}{c}s^{*} \\
(1)\end{array}$ & $\begin{array}{c}\Delta \\
(2)\end{array}$ & $\begin{array}{l}C_{A} \\
\text { (3) }\end{array}$ & $\begin{array}{l}\mathcal{X}_{\Delta} \\
(4)\end{array}$ & $\begin{array}{c}K_{b u c} \\
(5)\end{array}$ & $\begin{array}{c}\mathcal{K} ;[\text { Ref.-2] } \\
(6)\end{array}$ & $\begin{array}{c}\left(\mathrm{K}_{\mathrm{vb}}\right) / \\
x_{\mathrm{vM} .}=x / \\
\sqrt{2} \\
\left\{\mathrm{~N}_{\mathrm{xy}}\right\} \\
(7)\end{array}$ & $\begin{array}{l}K_{v i b} \\
(8)\end{array}$ & $\begin{array}{c}\beta_{\delta}= \\
\iint[w w \\
\quad \\
\left.\iint w\right] \partial x \partial y \\
(9)\end{array}$ & $\begin{array}{c}\omega=\sqrt{8 / 9} \\
(10)\end{array}$ & $\begin{array}{c}\text { Monitor }= \\
(\delta \mathcal{X} / \delta \Delta) / \Delta \\
\quad(11)\end{array}$ \\
\hline 1 & 0.00416 & - & 6.0875 & 240.34 & $4.0 \rho[4 \rho]$ & $\begin{array}{c}4.30 \\
\{5.66\}\end{array}$ & 240.3 & 0.616 & 19.74 & - \\
\hline 1.25 & 0.00619 & 1.06 & 4.337 & 161.60 & $3.78[>4 \rho]$ & & & & & -862 \\
\hline 1.50 & 0.00798 & 1.06 & 3.566 & 125.36 & $3.56[>4 \rho]$ & & & & & -431 \\
\hline 1.75 & 0.00948 & 1.055 & 3.174 & 105.73 & $3.375[>4 \rho]$ & & & & & -265 \\
\hline 2.0 & 0.0106 & 1.051 & 2.977 & 93.73 & $3.195[4 \rho]$ & & 93.7 & & 12.3 & -173 \\
\hline 2.25 & 0.0116 & 1.051 & 2.859 & 86.11 & $3.05[>4 \rho]$ & & & & & -118 \\
\hline 2.50 & 0.01236 & 1.0048 & 2.812 & 80.85 & $2.91 \rho$ & & & & & -61.8 \\
\hline 2.75 & 0.0130 & 1.046 & 2.797 & 77.02 & $2.79 \rho$ & & & & & -23.4 \\
\hline 3.00 & 0.0135 & 1.043 & 2.797 & 74.18 & $2.69[4 \rho]$ & $\begin{array}{c}1.98 \\
\{3.80\}\end{array}$ & 74.2 & & 10.96 & 0 \\
\hline 3.25 & $\begin{array}{c}0.0139 \\
(0.0135)\end{array}$ & 1.04 & $\begin{array}{c}2.83 \\
(2.797)\end{array}$ & 72.0 & $2.60 \rho$ & & & & & +82.5 \\
\hline 3.50 & 0.0135 & & & & 2.60 & & & & & \\
\hline
\end{tabular}

Table 5. New results of “CSCS” plate and $s^{*} ; N_{x}=\rho \mathcal{K}_{\text {cre }} ;$ “ $\mathcal{X}$ ” From “ $\Delta$ ”; $\left(\Delta_{i} \equiv w_{\text {shp }} / H\right)$.

\begin{tabular}{|c|c|c|c|c|c|c|c|c|c|c|}
\hline $\begin{array}{c}s^{*} \\
(1)\end{array}$ & $\begin{array}{c}\Delta_{s^{*}} \\
{[\operatorname{Ref}-1]} \\
(2)\end{array}$ & $\begin{array}{l}\mathrm{C}_{\mathrm{A}} \text {. } \\
\text { (3) }\end{array}$ & $\begin{array}{l}\mathcal{X}_{\Delta} \\
(4)\end{array}$ & $\begin{array}{c}K_{b u c} \\
(5)\end{array}$ & $\begin{array}{c}\mathcal{K}_{c r} ;[\text { Ref.-2] } \\
(6)\end{array}$ & $\begin{array}{c}X_{\mathrm{VM} .}=X / \\
\sqrt{2} \\
\left\{\mathrm{~N}_{\mathrm{xy}}\right\} \\
(7)\end{array}$ & $\begin{array}{c}\text { Factor }= \\
\iint \mathrm{ww} / \mathrm{w} \\
(8)\end{array}$ & $\begin{array}{c}K_{v b} \\
= \\
(9)\end{array}$ & $\begin{array}{c}\omega=\sqrt{9 / 8} \\
(10)\end{array}$ & $\begin{array}{c}\text { Monitor }= \\
(\delta \mathcal{X} / \delta \Delta) / \Delta \\
\quad(11)\end{array}$ \\
\hline 1 & $\begin{array}{l}0.001936 \\
{[0.00192]}\end{array}$ & - & 15.5 & 1032.18 & $6.75 \rho,[2.75]$ & $\begin{array}{l}10.96 \\
\{9.54\}\end{array}$ & 1.178 & 939 & 28.2 & - \\
\hline 1.15 & 0.0029 & - & 11.63 & 688.72 & $6.0 \rho,[]$ & & & & & \\
\hline 1.4 & 0.00465 & 1.059 & 7.68 & 430.35 & $5.68 \rho$, [] & & & & & $-2257(-2144)$ \\
\hline 1.65 & 0.00646 & 1.057 & 5.84 & 309.7 & 5.37 & & & & & $-1016(-903)$ \\
\hline 1.90 & 0.0081 & 1.054 & 4.91 & 246.5 & $5.09 \rho,[]$ & & & & & $-581(-468)$ \\
\hline 2.15 & 0.0095 & 1.051 & 4.54 & 209.6 & $4.68 \rho$, [] & & & & & $-257(-144)$ \\
\hline 2.4 & 0.0107 & 1.049 & 4.23 & 186.3 & $4.46 \rho$ & & & & & $-258(-145)$ \\
\hline 2.65 & 0.0117 & 1.046 & 4.05 & 170.7 & $4.27 \rho$ & & & & & $-180(-77)$ \\
\hline 2.9 & 0.0125 & 1.043 & 3.96 & 159.8 & $4.09 \rho$; stop!! & $\begin{array}{c}2.80 \\
\{5.79\}\end{array}$ & & & & $-113(0)^{\star *}$ \\
\hline 3.15 & 0.0132 & 1.043 & 3.92 & 151.79 & 3.92 & & & & & $-243(-130)$ \\
\hline
\end{tabular}

4.5. The "CSCC" Plate; $(a / b)=1$, Table 6

$$
w=Z\left[1-\cos \frac{m \pi x}{a}\right]\left[\sin \left(G \cdot \frac{y}{b}\right)+A \cdot y / b\right]
$$


in which, $m=2 ; G=4.5, A=0.977$; proceeding as before sample results are shown, (Table 6).

where for " $\mathcal{s}^{*}=1$ " the buckling load is $N_{x}=8.2 \rho$ and the vibration-factor, $\omega_{\text {csco }}$ is 31.97 (cf, 31.44 [12]; these are near exact results. The discrepancy in " $\omega$ " is truncation error that can become smaller as the $\mathrm{X}$-wave number, $\mathrm{m}$, goes beyond " 10 ". Results are highly accurate in displacement and buckling factors.

\subsection{The "SCSC" Plate, Table 7}

$$
w=Z \sin \frac{\pi x}{a}\left[1-\cos \frac{2 \pi y}{b}\right]
$$

Find that the aspect ratio, $s^{*}=0.866$ is critical where " $\chi_{x}=\chi_{Y}{ }^{\prime \prime}$.

Some results are sampled in Table 7; notice that " $N_{c r, s^{*}=1}$ is exact at 7.79" All displayed are very accurate.

\subsection{Deflection Limit}

In the Tables 3-6, the factor, $(\delta \mathcal{X} / \delta \Delta)$, exhibits a critical stationary-point, Figure 7 , where " $\Delta_{\text {limit }}$ " is sampled.

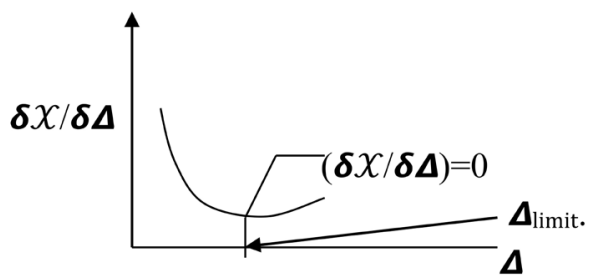

Figure 7. $(\delta \mathcal{X} / \delta \Delta)-\Delta$ : graph to monitor solution.

Table 6. New results of "CSCC" and " $\mathcal{c}^{*} ; N_{x}=\rho \mathcal{K} ;$; $\mathcal{X}$ ” by " $\Delta$ "; $\left(\Delta_{i} \equiv W_{\text {sh }} / H\right)$.

\begin{tabular}{|c|c|c|c|c|c|c|c|c|c|c|c|c|}
\hline $\begin{array}{c}\mathcal{S}^{*} \\
(1)\end{array}$ & $\begin{array}{c}\Delta_{s^{*}} \\
{[\text { Ref-18, Oba et al] }} \\
(2)\end{array}$ & $\begin{array}{l}C_{A} \\
\text { (3) }\end{array}$ & $\begin{array}{l}\mathcal{X}_{\Delta} \\
(4)\end{array}$ & $\begin{array}{l}K_{b u} \\
(5)\end{array}$ & $\begin{array}{c}\mathcal{K}_{c r} \\
;[\text { Ref.-2] } \\
(6)\end{array}$ & $\begin{array}{c}x_{\mathrm{VM} .}= \\
X / \\
x / \sqrt{ } 2 \\
\left\{\mathrm{~N}_{\mathrm{xy}}\right\} \\
(7)\end{array}$ & $\begin{array}{l}K_{v i b} \\
(8)\end{array}$ & $\begin{array}{c}\beta_{\delta}= \\
\iint(\mathrm{ww} / \\
\mathrm{w}) \\
(9)\end{array}$ & $\begin{array}{c}\omega=\sqrt{8 / 9} \\
(10)\end{array}$ & $\begin{array}{c}\text { Monitor }= \\
\delta \mathcal{X} / \delta \Delta \\
\quad(11)\end{array}$ & $\mathrm{C}$ & $\begin{array}{c}\mathrm{C} \\
\mathrm{s} \\
\end{array}$ \\
\hline 1 & $\begin{array}{c}0.0016 \\
{[0.00161]}\end{array}$ & - & 20 & 1627 & $\begin{array}{l}8.2 \rho, \\
{[8.4]}\end{array}$ & $\begin{array}{c}14.1 \\
\{11.66\}\end{array}$ & 1578 & 1.544 & 31.97 & & & \\
\hline 1.25 & 0.0027 & & & & & & & & & & & \\
\hline 1.5 & 0.00355 & & & & & & & & & & & \\
\hline 1.75 & 0.00415 & & & & & & & & & & & \\
\hline 2.0 & 0.00488 & & & & & & & & & & & \\
\hline 2.25 & & & & & & & & & & & & \\
\hline 2.50 & & & & & & & & & & & & \\
\hline 2.75 & & & & & & & & & & & & \\
\hline 3.0 & & & & & & & & & & & & \\
\hline 3.25 & & & & & & & & & & & & \\
\hline
\end{tabular}


Table 7. New results of "SCSC" Vs “ $s^{* ” ;} N_{x}=\rho \mathcal{K} ;$ “ $\mathcal{X}$ ” by “ $\Delta$ "; $\left(\Delta_{i} \equiv W_{\text {sh }} / H\right)$.

\begin{tabular}{|c|c|c|c|c|c|c|c|c|c|c|c|c|}
\hline $\begin{array}{l}D s^{*} \\
(1)\end{array}$ & $\begin{array}{c}\Delta_{s^{*}} \\
{[\text { Ref-1, }]} \\
(2)\end{array}$ & $\begin{array}{l}C_{A} \\
\text { (3) }\end{array}$ & $\begin{array}{l}\mathcal{X}_{\Delta} \\
(4)\end{array}$ & $\begin{array}{l}K_{b u} \\
=H \\
(5)\end{array}$ & $\begin{array}{c}\mathcal{K}_{c r} \\
;[\text { Ref.-2] } \\
(6)\end{array}$ & $\begin{array}{c}x_{\mathrm{vM}}=x / \\
x / \sqrt{ } 2 \\
\left\{\mathrm{~N}_{\mathrm{xy}}\right\} \\
(7)\end{array}$ & $\begin{array}{l}K_{v i b} \\
(8)\end{array}$ & $\begin{array}{c}\beta_{\delta}= \\
\iint(w w / \\
w) \\
(9)\end{array}$ & $\begin{array}{c}\omega=\sqrt{8 / 9} \\
(10)\end{array}$ & $\begin{array}{c}\text { Monitor }= \\
\delta \mathcal{X} / \delta \Delta \\
\quad(11)\end{array}$ & $s$ & e \\
\hline 0.866 & $\begin{array}{l}0.00163 b^{4} \\
{[0.0016 . .]}\end{array}$ & 1 & 15.5 & 1224 & 8.0 & $\begin{array}{l}10.96 \\
\{11 .\}\end{array}$ & & & & & & \\
\hline 1.0 & $\begin{array}{c}0.001936 \\
{[.00192]}\end{array}$ & 1.03 & 13.44 & 1033. & $\begin{array}{c}7.79 \\
{[7.79]}\end{array}$ & & & & & -6774 & & \\
\hline 1.25 & 0.00234 & 1.06 & 11.79 & 855 & 7.35 & & & & & -1833 & & \\
\hline 1.50 & 0.0026 & 1.059 & 11.24 & 771 & 6.95 & & & & & -1833 & & \\
\hline 1.75 & 0.00276 & 1.055 & 11.17 & 724 & 6.57 & & & & & -438 & & \\
\hline 2.0 & 0.00287 & 1.052 & 11.30 & 696 & $\begin{array}{c}6.24 \\
{[7.15]}\end{array}$ & $\{8.8\}$ & & & & $\begin{array}{l}+2091 ; \\
{ }_{* *}^{*} \text { stop }\end{array}$ & & \\
\hline 2.25 & 0.00295 & 1.05 & 11.54 & 677 & 5.94 & & & & & & & \\
\hline 2.5 & 0.003 & 1.047 & 11.88 & 663 & 5.65 & & & & & & & \\
\hline
\end{tabular}

The minimum buckling load, for "very-long" plates, is indicated at that point, whatever the values of " $m, n$ or $s^{*}$. The relative weakness of a plate is indicated in bending-buckling-vibration-analyses [1] [17]. By Yaghoobi [3] the buckling strength of the "SSSS" at $s^{*}=1.5$ is 91 -percent of the value at $s^{*}=1$; this is the kind of statement sought-after here. This sits well with the ratio of 89-percent in Table 3; also experiments [6], showed a " $s^{*}=2$ plate was only some 40 -percent as strong as a " $\mathcal{S}^{*}=1$ " one. In "plate buckling solution based on characteristic deflection-factors", [7], relevance of deflection was focused on. Here, the analysis starts with beam-strip solutions that are already fully known; for simply supported strip, $\Delta_{c}=5 / 384=0.01302$ and the "SSSS" plate ends in this value when it is very long or very short; for example check the $\Delta_{c}=0.0135$ in Table 3 in the "SSSS" at $s^{*}=3.5$; so the size of " $\Delta$ " can, also, be used to terminate solutions.

\subsection{Emulating the "SSSS-Plate" for $\omega_{\text {vibration-Calibration }}$}

Once the solution of the "SSSS" plate is found, it is only necessary to confirm the buckling-vibratory deflection, $\left(\Delta_{\text {next }}\right)$ of any next-plate in any other support configuration so as to emulate the "SSSS". By Equation (9),

$$
\mathfrak{M}_{\text {new }} \omega_{\text {new }}^{2} \Delta_{\text {new }}=\mathfrak{M}_{\text {ssss }} \omega_{\text {ssss }}^{2} \Delta_{\text {ssss }}
$$

Equation (31) is profoundly important; it implies that if in the process of vibration a boundary condition reduces from a higher to a lower one, the plate will not collapse provided there is no significant serviceability damage. A "CCCC" plate reducing to "SCCC" only brings higher amplitude until inspection and retrofitting.

The buckling deflection is recommended because $[K]$ is already known, at this stage, and from Equation (19b), “ $\Delta=Z w_{s h p, x} \cdot w_{s h p, y}$ ”. 


$$
Z=\frac{q^{*}}{H}
$$

For example, find the $\left(\omega_{\text {cccc }}^{2}\right)$ from $\left(\omega_{\text {ssss }}^{2}\right)$ as follows,

From Table 3, “ $\Delta_{\text {buck,cccc }}=0.00128$ "; So,

“ $\omega_{c c c c}^{2} \rightarrow 389.635 \times 0.00416 \times(1 / 0.00128)=1266.3 ;$ so, $\omega_{c c c c}=35.585 ;$ cf, 35.112, Xing [14]; 35.8, [13]”

Using Timoshenko and Kreiger's, [1] deflection factors make very little difference, that is

$$
\text { “ } \omega_{c c c c}^{2}=389.6 \times 0.00406 \times 1 / 0.00126=1255.38 ; \omega_{c c c c}=35.43 . ”
$$

It is now easy to build up Table 8 covering many plates; extendable; these results are usually more exact than those from independent computations from, “ $[K]\{\Delta\}=\omega^{2}[\mathfrak{M}]\{\Delta\} "$

The method easily detects error entries; in Xing and Liu's [14] the "CSCC/2" plate as " $\omega=24.1$ " was in error; the correct result is “ $\omega=18.2$ "; the difference is large. The plate "CCCC/2" which has " $\omega_{\text {ccccl } 2}=24.36$ " is much stiffer than "CSCC/2", by their deflection results. So, there is near-perfect match for Xing and Liu's results with the "SSSS" as calibrator.

\subsection{Direct Evaluation of Free Vibration from Buckling Stiffness}

This may be achieved by invoking Equation (9). Since buckling attributes are already listed in the Tables, it is only necessary to compute some additional sympathetic harmonics to evaluate the results. Already found results and new ones will be established easily. Indeed, Equation (9a) led to the "CCCC" independent results in Table 3.

\section{(a) Practical Sampling of Vibration-Harmonics}

A “ 3,1 " mode in the "SSSS" means three half-sine waves. The equations may be re-visited to find " $\left(\omega_{s s s s, 3,1}\right)^{2}$."

Test the "CCCC" for $\left(\omega_{c c c c, 2,1}\right) ; a / b=1$. This is not an important harmonic as it does not amplify the fundamental as shown in Figure 8. The "CCCC" curve in the X-direction splits into two modes of "CCSC" each;

using existing principle to analyse one "CCSC" for " $a=1 / 2$ and $b=1$ ".

" $\{$ With the mode, $Q=(\sin 4.5(x / a)+0.977 x / a)(1-\cos 2 \pi y / b)$; find $\left[H_{x x} \rightarrow 0.89 G^{4} / a^{4}=5839 ; H_{x y}=0.59 n^{2} G^{2} \pi^{2} /\left(a^{2} b^{2}\right)=1886.7\right.$;

$\left.H_{y y}=0.507 n^{4} \pi^{4} / b^{4}=790.1 ; H=8516\right]$

$Z=1 / H=0.000117 ; \Delta=Z W_{\text {shp }} ; W_{\text {shp }}=1.34 \times 2.0$ at “ $x=0.35, y=0.5$ "; So, $\left.\Delta_{2,1}=0.000315^{\prime \prime}\right\}$.

Finally, calibrating from the "SSSS".

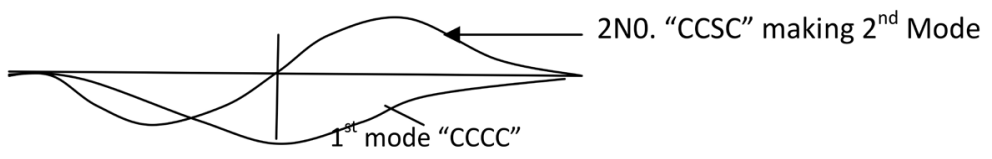

Figure 8. 1st and 2nd modes of the "CCCC" plate. 
Table 8. New results; vibration frequency $(\omega)$ derivable from the SSSS-case: calibration.

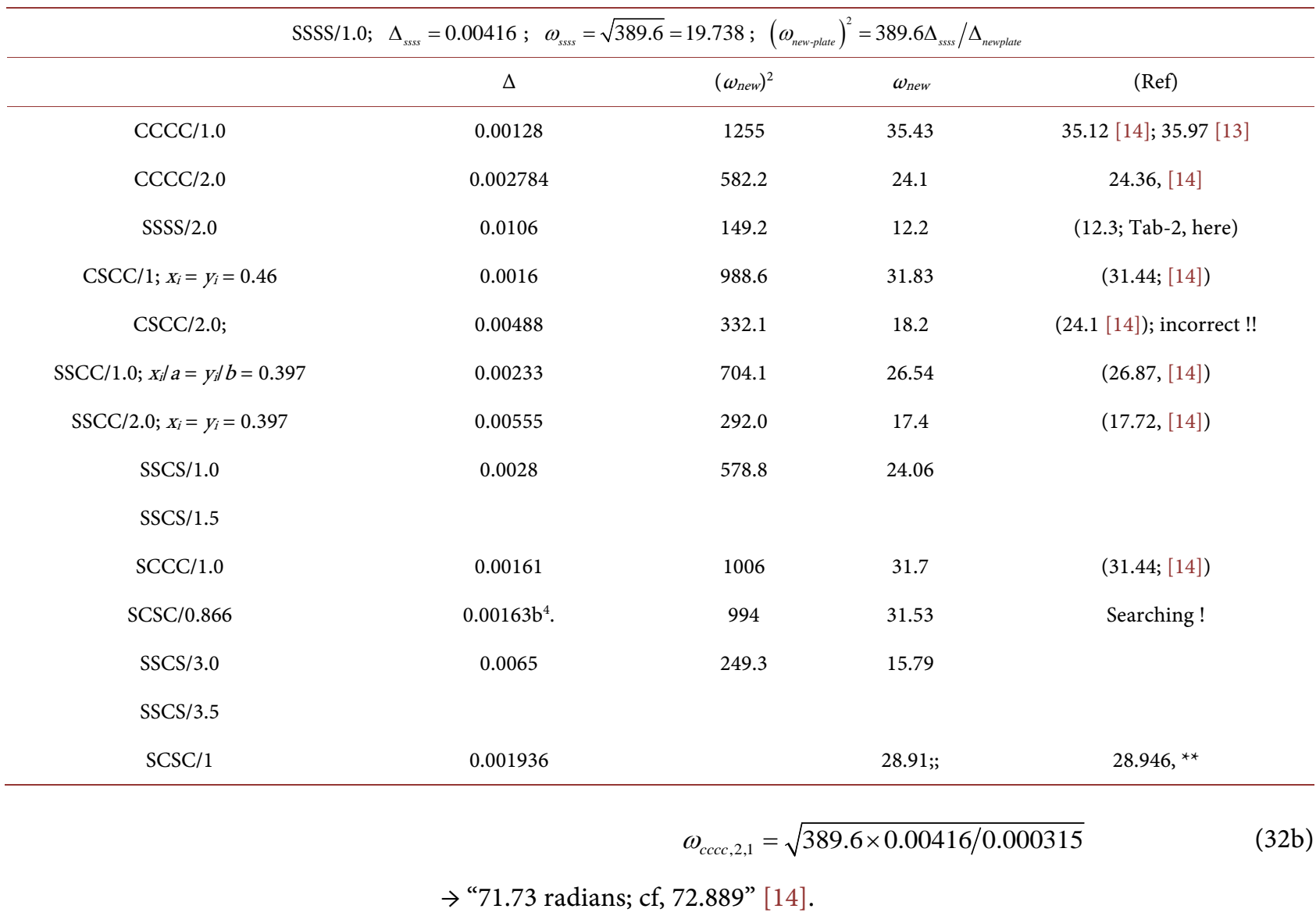

\subsection{After-Shocks (Harmonics) by Calibration from "SSSS"}

For very speedy processing, Equation (28) for the "SSSS" is modified for other plates by interpreting the lengths " $a, b$ " as effective Euler-length-averages between waves; some refinement will be possible (Figure 9).

$$
\begin{aligned}
\omega^{2} & =\pi^{4} \frac{D}{\mathfrak{M}}\left[J^{2}\right] \\
J & =\frac{1}{a^{2}}+\frac{1}{b^{2}} \\
\omega^{2} & =\pi^{4} \frac{D}{\mathfrak{M}}\left[S^{2}\right]
\end{aligned}
$$

where,

$$
S=\frac{1}{L_{e-a v-x}^{2}}+\frac{1}{L_{e-a v-y}^{2}}
$$

For simplicity, the approximation in Equation (34) for the harmonic $(\geq 3)$ is employed $($ mode $=$ number of peaks)

$$
L_{e-a v}=\frac{1}{\text { mode number }} .
$$


Results improve fast as harmonics increase beyond " 2 ".

Some typical results are listed in Table 9 below.

\section{Higher Modes in Buckling; the "SSSS"}

Table 4 has already solved this problem, relying only on the fundamental wave, $m=n=1$, but the question may be posed: what is the failure mode for a given aspect ratio? In combining two neighboring symmetrical waves, the tried Dunkerley's approximate resultant is used to study this question.

For example; $s^{*}=2.5$, try two waves, placed between the actions, 1 ); $m=1, n=1 \equiv C_{s^{*}=2.5, m=1}$, or $C_{2.5,1}$; and 2) $m=3, n=1 \equiv C_{2.5,3}$; In details.

1) $\left[C_{2.5,1}: H_{x x}=1.54 ; H_{x y}=19.2 ; H_{y y}=60.1 ; H=80.8 ; \mathcal{X}_{x}=0.974\right.$; $\left.\mathcal{X}_{y}=6.0875 ; \mathcal{X}_{a v}=3.5308 ; N_{x x}=82.95=8.4 \rho\right]$

2) $\left[C_{2.5,3}: H_{x x}=374 ; H_{x y}=519 ; H_{y y}=180.2 ; H=1073 ; \mathcal{X}_{x}=26.3\right.$; $\left.N_{x x}=4.13 \rho\right]$

Combining by Dunkerley's;

$N_{c r}=8.4 \times 4.13 /(8.4+4.13)=2.77 \rho, \mathrm{cf}, 2.91$ in Table 4 above. This is a failsafe combination.

So, it can be said the waves. $(m=1, n=1 ; m=3, n=1)$ combine for solution at aspect ratio, " $s$ * $=2.5$ "

\section{Discussing the Kirchhoff-Love Plate Field-Sheet}

Several examples of interactive field-sheets are presented to aid design; Tables 3-7. To start the field-sheet first detect the aspect-ratio for exact spot uni-axial buckling result at, Figure 4, " $\chi_{x}=\chi_{y}$ ", complete in displacement-factor and curvature-value $(\chi)$. Exact harmonic strip functions combinations are found sufficient to re-establish Euler's strip solutions in plates; hyperbolic functions, with more unknowns, are not harmonic and are ruled out when exact results have already been found. Table 2, and similar ones; to prove that the "Sine-curve" is the instability curve, first pretend that buckling curve is not a Sine-curve and iterate $[K]\{\Delta\}=\{M\}$ to a steady state., as in Table 2

Some results are self-checking; the "CSCC (Tab-5) and SCCC" in Section-4.1 are close; by 1968 the latter was only found in Russia [18] termed "approximate" in Leissa's, [2] using,

$$
w=\left[\cos (2 m-1) \frac{\pi x}{2 a}-\cos (2 m+1) \frac{\pi x}{2 a}\right]\left(1-\cos \frac{2 \pi y}{b}\right)
$$

the present study, explained in Section-4.1; replaces the X-function, to yield equation (24).

Both functions lead to approximately same results for limited aspect ratios. At $s^{*}=1$, “ $N_{c r} \equiv 8.73$ here, and 8.986" in Ref. [2]; only the present method is able to track the strength up to $s^{*}=\infty$ as demonstrated in Table 5 for CSCC; Oba, et al., [20] supplied the comparable displacements; omitted in Timoshenko's works. 
Table 9. Practical Results on some harmonic-waves $(\omega)$.

\begin{tabular}{|c|c|c|}
\hline Plate (mode); $s^{*}$ & $(\omega)$ & [Ref] \\
\hline $\operatorname{CCCC~}(3 / 1) ; 1$ & 128.49 & $131.6,[13]$ \\
\hline $\operatorname{CCCC}(5 / 3) ; 1$ & 335.58 & - \\
\hline $\operatorname{SSSS}(5 / 1) ; 1$ & 256.6 & 255.47 [19] \\
\hline $\operatorname{SSCC}(3 / 1), 1$ & 108.75 & 114.58. [6] \\
\hline $\operatorname{CCCC~(11/9);~} 1$ & $42,470.0$ & - \\
\hline
\end{tabular}

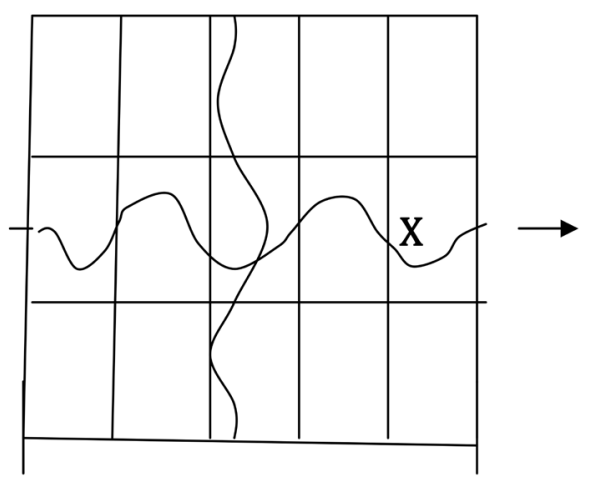

Figure 9. "CCCC"-plate-harmonics: mode-5/3 in X, Y.

\section{Conclusions}

1) The Kirchhoff-Love plate, in a capacity-analysis, has produced very accurate field solutions in buckling displacement-factors interchangeable with elastic bending ones. This closeness of the results was not widely known in the past. Relative displacement-factors are employed in very accurate solutions for buckling, pure-shear and vibration.

2) For self-checking, it is demanded the solution buckling-mode be developable into recognizable elastic deflection-factor; for example, for the Euler bar $\Delta=$ 0.0103077 checking with the Euler-Bernoulli beam of $\Delta=0.01302$; for the “CCCC" plate, $\Delta=0.00128$ checking with Timoshenko's, $\Delta=0.00126$; etc.

3) Tracking buckling by displacement-factors has brought to light existing large errors in some existing solutions; this study confirms that the strength of the "SSSS" plate in uni-axial compression decreases from 4 -units at $a / b=1$ to 2.6 units at $a / b \rightarrow \infty$, and not a constant 4 -units; the difference is huge.

4) The present spring-capacity-solution has brought more meaning to pure-shear plate buckling relying on von Misses stress condition; the present pure-shear solution for the "SSSS" plate of " $N_{x y}=3.6+2.5 /(a / b)^{2}$ " was never found before. The existing literature value of " $N_{x y}=5.3+4 /(a / b)^{2}$ " was found in this study to match the strength of the "CSCS" plate; this was a major issue in the support-zone stability study of webs in beams.

5) The plate spring values have been shown to produce exact and near-exact solutions for vibration-factors- $\omega$. The presence of relative-displacements in the

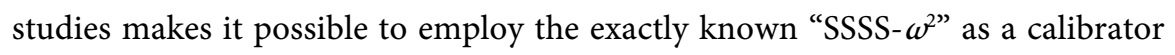


for all other plates.

6) From the foregoing, the Kirchhoff-Love plate field-sheet is readily completed for the design of many structures-bridges, buildings and associated structures.

7) The stiffness solution method, $[K]\{\Delta\}=\{F\}$, akin to finite element solution, has worked perfectly when applied to closed form evaluation of the KirchhoffLove plate. Characteristic buckling displacement-factor from known bucklingmode was targeted but in the end, these factors were found within one-percent of final elastic bending values; there is yet more to be said. There is now a unique characteristic buckling displacement (wave-amplitude frozen in the first mode of vibration) distinct from the rigorous elastic displacement; the former standing just proud of the latter.

\section{Acknowledgements}

The Niger Delta Development Commission, Nigeria Government, in the "Kaa-Ataba" Road and bridge-works assisted technically and financially towards this study.

\section{Conflicts of Interest}

The author declares no conflicts of interest regarding the publication of this paper.

\section{References}

[1] Timoshenko, S. and Woinowsky-Krieger, S. (1959) Theory of Plates and Shells. 2nd Edition, McGraw-Hill Kogakusha, Ltd.

[2] Leissa, A.W. (1985) Buckling of Laminated Composite Plates and Shell Panels. Flight Dynamics Laboratory, Wright-Patterson Air Force Base.

[3] Yaghoobi, H. (2013) Buckling Analysis of Three Layered Rectangular Plate with Piezoelectric Layers. Journal of Theoretic and Applied Mechanics, 51, 813-826.

[4] Pride, R.A. and Heimeri, G.J. (1949) Plastic Buckling of Simply Supported Compressed Plates (NACA Technical Note-1817). National Aeronautics and Space Administration, Washington DC.

[5] Nishino, F., Ueda, Y. and Tall, L. (1966) Experimental Investigation of the Buckling of Plates with Residual Stresses. Fritz Laboratory Reports, Paper 173, 1-21.

[6] Featherston, C.A. and Ruiz, C. (1998) Buckling of Flat Plates under Bending and Shear. Proceedings of the Institution of Mechanical Engineers, Part C: Journal of Mechanical Engineering Science, 212, 249-261.

[7] Johnarry, T.N. and Ebitei, F.W. (2020) Plate Buckling Solution Based on Pre-Buckling Deflection Factor. European Journal of Applied Engineering and Scientific Research, 8, 1-8.

[8] Johnarry, T.N. and Ebitei, F.W. (2020) Von Misses Pure Shear in Kirchhoff s Plate Buckling. Open Journal of Civil Engineering, 10, 105-116.

https://doi.org/10.4236/ojce.2020.102010

[9] Johns, D.L. (1971) Shear Buckling of Isotropic and Orthotropic Plates: A Review. Her Majesty's Stationery Office, London.

[10] Rockey, K.C. (1967) Shear Buckling of Thin-Walled Sections. In: Chilver, A.E., Ed., 
Thin- Walled Structures, Chatto and Windus, London.

[11] Rayleigh, L.J.W. (1945) The Theory of Sound. First American Edition, Dover Publications, New York.

[12] Ballal, B. (1966) Vibration of Rectangular Plates. A Thesis Submitted in Partial Fulfillment of the Master of Science, Rice University, Houston.

[13] Leissa, A.W. (1969) Vibration of Plates. NASA-SP160, National Aeronautics and Space Administration, Washington DC.

[14] Xing, Y.F. and Liu, B. (2009) New Exact Solutions for Free Vibration-Orthotropic Plates. Composite Structures, 89, 567-574.

https://doi.org/10.1016/j.compstruct.2008.11.010

[15] Onwuka, D.O., Ibearugbulem, O.M., Abamara, A.C., Njoku, C.F. and Agbo, S.I. (2016) Free Vibration Analysis of an All-Round Clamped Rectangular Plate Using Taylor-Mclaurin Shape Function. American Journal of Engineering Research, 5, 190-197.

[16] British Standards Association (1978) BS 5400. 1978 Part 2 Appendix C: Permissible Vibration for Foot Bridges and Cycle-Track Bridges. British Standards Association, London.

[17] Johnarry, T.N. (2013) Buckling by Constant Stiffness and Curvature-Deflection Resonance. Journal of Civil Engineering Research, 3, 1-15.

[18] Brukva, N.F. (1968) Stability of Rectangular Orthotropic Plates. Soviet Applied Mechanics, 4, 47-51. (in Russia) https://doi.org/10.1007/BF00889196

[19] Batoz, J.L., Bathe, K.J. and Ho, L.W. (1980) A Study of 3-Node Triangular Bending-Elements. International Journal for Numerical Methods in Engineering, 15, 1771-1812. https://doi.org/10.1002/nme.1620151205

[20] Emmanuel, O., Anyadiegwu, P.C., George, A.G.T. and Nwadike, E.C. (2018) Pure Bending Analysis of Isotropic Thin Rectangular Plates Using Third-Order Energy Functional. International Journal of Scientific and Research Publications, 8, 254262. https://doi.org/10.29322/IJSRP.8.3.2018.p7537 


\section{Nomenclature}

$a, b$ : rectangular plate dimensions in $\mathrm{X}, \mathrm{Y} ; a \equiv$ longer side;

$\delta b$ : change in width of plate;

$s^{*}$ : aspect ratio, $a / b$;

$a, b$ : rectangular plate dimensions in $\mathrm{X}, \mathrm{Y} ; a \equiv$ longer side;

$s^{*}$ : aspect ratio, $a / b$;

$E$ : Young's modulus of elasticity;

$D$ : flexural rigidity of plate, (isotropic); $D=E t^{3} / 12(1-\mu)^{2}$;

$D^{*}=E I / b_{e}$;

$N$ : axial compression $=\mathcal{K} \cdot \rho$;

$\rho=D \pi^{2} / b^{2}$;

$t$ : thickness of plate;

$\mu$ : poisson's ratio;

$w$. general deflection symbol;

$W_{\text {shp-x }}:$ shape-function in $X$-direction;

$\Delta_{i}$ : displacement value at point- $I$;

$Z$ : displacement-amplitude;

$W_{X X-r}:$ relative curvature in $X$-direction ;

$W_{y y-r}:$ relative curvature in $Y$-direction;

$W_{X X-r} / W$. relative-curvature/deflection ratio; must be a scalar for any solution;

XX-SC, YY-CC; plate simply and clamped on X-X; and clamped-clamped on $\mathrm{Y}-\mathrm{Y}$;

$r_{\text {cap }}$ : capacity ratio of axes as, $\left(\partial^{4} w / \partial x^{4}\right) /\left(\partial^{4} w / \partial y^{4}\right)$;

$K,(H)=D\left(\partial^{4} w / \partial x^{4}+2 \partial^{4} w / \partial x^{2} y^{2}+\partial^{4} w / \partial y^{4}\right)=$ actual domain; spring-stiffness of plate;

$\mathcal{X}$ : curvature;

$\mathfrak{M}$ : mass;

$\omega$ : Vibration-factor or angular velocity;

$\sigma:$ stress symbol;

$F$ : Generalized applied forces;

$q,\left(q^{*}\right)$ : rate of loading;

r. EI/ L;

$a^{*}: E A / L$ 